\title{
Espaço público: acção politica e práticas de apropriação. Conceito e procedências
}

\section{Public space: political action and appropriation practices. Concept and precedence's}

\author{
Carla Alexandra Filipe Narciso \\ Universidade de Lisboa, Faculdade de Letras, Departamento de Geografia, Lisboa, \\ Portugal
}

\begin{abstract}
Resumo
Neste trabalho pretendemos problematizar o conceito de espaço público, como objecto central considerando a sua análise a dois níveis de interpretação: enquanto lugar da acção política e de expressão de modos de subjectivação não identitários, e como lugar por excelência da comunicação, da democracia e como lugar de encontros multi-sociais. Examinamos as dimensões da forma, da apropriação e do lugar, assim como a integração dos conceitos, com o intuito de entender como se organiza o espaço do cidadão e o espaço da política, que se sobrepõem. Importa entender como se organiza o espaço público nas diversas dimensões face ao envolvimento dos actores institucionais e aos modos de reprodução capitalista subjacente às acções do poder público e da iniciativa privada, pois são estes que tem o poder de materializar a forma do espaço e induzir as expressões sociais dos indivíduos.
\end{abstract}

Palavras-chave: Espaço público, Forma, Apropriação, Lugar.

\begin{abstract}
In this paper, we won't to aboard the problematic of the concept of public space, how central object to consider your analysis in to two level's interpretation: how place of action politic and the expression of the subjectivity not identities modes, and how place for excellence to the communication, to the democracy and how place for multi-socials meetings. To examine the dimensions of the shape, the appropriation and the place, in this way, the integration of the concepts, with the intuition to understand how the space of the man and the politic to organized who to superimposing. Import to understand how to organized the public space in the many dimensions face to involvement to the institutionalizes actors and to the modes of capitalism reproduction subjacent to the actions of the public power and to the private initiative, because to be this who have the power to materialized the shape of space and to induce the socials expressions of to the individuals.
\end{abstract}

Keywords: Public space, Shape, Appropriation, Place. 
As mudanças globais das cidades contemporâneas geraram uma nova atitude na compreensão do espaço público. A transformação da sua estrutura económica e social, a sua organização espacial e a sua configuração formal marcam a produção de novas territorialidades através de visões antagónicas: actores institucionais versus cidadãos. Neste contexto, o espaço público ganha um novo significado, politico ideológico, social e estrutural. Analisar o conceito de espaço público, vai no sentido de entender a sua estruturação na evolução da sociedade contemporânea e, consequentemente, na problemática equacionada. Reflectir sobre o conceito de espaço público obriga a pensar o espaço como um recurso, um produto e como uma prática (sensual, social, politica e simbólica). I mporta igualmente reflectir sobre a apropriação e utilização do espaço (tanto a nível material como simbólico), a transformação de espaços existentes e a produção de espacialidades inéditas, em correspondência com distintos projectos culturais emergentes.

\section{O conceito de espaço público}

O termo Espaço Público surge cada vez mais como o locus de uma base de discussão transversal às diversas ciências, suscitando permanentemente novas abordagens. Actualmente têm surgido diversos estudos que utilizam como cerne da questão o espaço público urbano. Quer ao nível da abordagem da sua estrutura, função, projecto, o seu carácter semântico e social, tem-se conduzindo pelo estabelecimento de intercalar várias de estas perspectivas de análise, por se entender que o espaço público acarreta diversos significados e dimensões que não existem isoladas. Segundo Ascher (1995), o termo de espaço público aparece pela primeira vez num documento administrativo em 1977, no quadro de um processo de intervenção pública, agrupando na mesma categoria os espaços verdes, as ruas pedonais, as praças, a valorização da paisagem urbana, o mobiliário urbano. O espaço público é considerado como aquele espaço que, dentro do território urbano tradicional (especialmente nas cidades capitalistas, onde a presença do privado é predominante), sendo de uso comum e posse colectiva, pertence ao poder público. Serpa (2004) refere-se ao conceito de espaço público como sendo em si mesmo o espaço da acção política ou, pelo menos, da possibilidade da acção politica na contemporaneidade.

O espaço público é o espaço por excelência da/na cidade. Conhecemos a cidade através do espaço público. Nele aprendemos a caminhar e a ver a cidade. Indovina (2002) assume esta posição e define alguns pontos de vista, na qual justifica o espaço público como a cidade. De uma forma geral, considera que o espaço público constitui um factor importante 
de identificação, que conota os lugares, manifestando-se através de símbolos e em segundo lugar, refere o espaço público como o lugar da palavra, como lugar de socialização, de encontro e também onde se manifestam grupos sociais, culturais e políticos que a população da cidade exprime. Borja (2003) assume a mesma posição que Indovina e reivindica a cidade como espaço público, negando-se a atribuir ao mesmo apenas um só uso especializado. Defende que "[...]é a cidade no seu conjunto que merece a consideração do espaço público[...]" (BORJA, 2003, p.29), e que este é o lugar por excelência da sociabilização.

O conceito de espaço público é de alguma complexidade, pelo que uma definição específica seria sempre redutora. Alexandra Castro (2002), refere que, do ponto de vista sociológico o termo de espaço público só por si se revela de alguma complexidade. À parte do que engloba o conceito, o próprio termo levanta algumas questões para esta investigadora. Alexandra Castro discute inclusive, se a utilização do termo se deveria empregar no plural ou no singular ou se é correcto denominar espaço público ou "espaço do público". Na concepção de esta autora, o espaço público deve ser visto segundo duas visões antagónicas: 1) retorno em força dos espaços públicos como elementos centrais dos projectos urbanos e 2) que o esquecimento da sua dimensão pública pode estar na origem da crise do laço social e da crise de cidadania que hoje se conhece. No primeiro ponto, o retorno em força dos espaços públicos, prende-se com os grandes projectos de renovação urbana. Relativamente ao segundo ponto, Ascher (1995) segue a mesma ideia, referindo que a problemática dos espaços públicos resulta num primeiro momento de uma transformação das práticas urbanas, e dos usos e status dos diversos espaços metapolitanos. As noções de público e privado transformam-se, as partilhas espaciais e jurídicas redefinem-se. As distinções estabelecidas público/privado são redefinidas pela desagregação social e funcional dos bairros, o desenvolvimento de novas centralidades, as novas sociabilidades mais fundadas nas afinidades que nas proximidades físicas, a integração para a habitação com funções outrora exteriores, o desenvolvimento dos transportes rápidos, a quase generalização do uso do automóvel, as concessões mais numerosas dos trabalhos e serviços públicos, etc.

$\mathrm{Na}$ actualidade questiona-se muito a posição do público versus privado no entendimento de espaço público. Para entender a noção de espaço público é necessário entender o que é público. E o que é público? Talvez essa questão se coloque porque cada vez mais a linearização que se põe entre os dois conceitos se cruza e começa a haver uma maior privatização de diferentes espaços 1.

Para entendermos melhor a dimensão dos conceitos de espaço público, partindo igualmente do segundo pressuposto que Castro (2002) refere, recorremos às definições de Arendth (1972) e Habermas (1984). Quando 
Castro (2002) refere que num primeiro momento existe um retorno em força dos espaços públicos como elementos centrais dos projectos urbanos, entra um pouco na teoria de Arendth, onde se enquadram os actores institucionais, em que o espaço público se encontra enquanto lugar da acção politica e de expressão de modos de subjectivação não identitários, (Hannah Arendth, 1972), ou seja, muito ligado ao que Lefevbre (1973) refere de espaço programado2; e o espaço público como lugar por excelência da comunicação e encontro multi-sociais, da democracia e do uso livre (Jürgen Habermas, 1984), mas que hoje se encontra numa profunda crise identitaria, e aqui ligado ao que Alexandra Castro (2002) define no segundo ponto.

O espaço público constitui ou deveria constituir uma fonte de forte representação pessoal, cultural e social, pois trata-se de um espaço simbólico onde se opõem e se respondem aos discursos, na sua maioria contraditórios, dos agentes políticos, sociais, religiosos, culturais e intelectuais que constituem uma sociedade.

A necessidade de distinguir o público do privado, passa pelas mudanças que os espaços públicos estão a sofrer fruto das alterações nas formas de consumo, onde estão necessariamente implícitos os centros comerciais, que de algum modo se prendem com a privatização. As políticas urbanas de intervenção, têm supra influência nestas mudanças estruturais da dimensão social do espaço público, pois para além de fomentarem a proliferação destes espaços, reduzem a qualificação dos espaços públicos a meros sobejos da urbanização, ou então actuam vinculados a um "zonamento" de intervenção estratégico. Os modos de reprodução do capital através do urbanismo e concretamente nas estratégias de politicas de intervenção, em que o espaço público surge como o mote de indução do conceito das estratégias de promoção, cria-se na base de sustentação da especulação imobiliária. Segundo Carlos (2001), estas contêm implicações importantes no uso e na apropriação do espaço urbano, poislimitam as condições e as possibilidades de uso do espaço público pelos seus habitantes, isto é, cada vez mais os espaços urbanos, transformados em mercadoria, são destinados à troca, o que significa que a apropriação e os modos de uso tendem a se subordinar (cada vez mais) ao mercado.

O caso dos projectos de renovação urbana em que se dá grande ênfase ao espaço público, não é mais do que uma estratégia de acumulação de capital e um modo da reprodução capitalista contemporâneo subjacente às acções do poder público e da iniciativa privada, instituindo-se através da produção-consumo. Este tipo de atitudes tem forçosamente implicações na forma dos espaços. Reduzem-se aspectos como a acessibilidade, visibilidade e funcionalidade, pois implicitamente surgem outras demandas nas vivências dos espaços. Ribeiro (2000, p.2) aponta que a perda de vivência do espaço público se prende com a 
Difusão de uma sensação de insegurança perante espaços demasiado abertos e pouco controlados, reveladores de uma certa agorafobia urbana, a concentração da população em áreas suburbanas distantes das zonas centrais, a criação de infra-estruturas de circulação intra-urbanas.

A mesma autora refere que esta perda está igualmente associada aos avanços tecnológicos no âmbito das telecomunicações, que representam processos de mudança que podem reflectir-se num retraimento do espaço público, sobretudo no que diz respeito à sua componente física, e por conseguinte à sua forma.

Por isso se torna importante entender como a forma influi na apropriação dos espaços, para se poder debater a importância do urbanismo e dos projectos de intervenção do espaço público. Contudo, existe uma alienação dos actores institucionais relativamente às necessidades das populações, pois as imagens criadas através das estratégias de renovação urbana, se concebem à margem das mesmas, fazendo muitas vezes com que as pessoas não se identifiquem com os lugares, podendo mesmo afirmar-se, que com o tempo, a apropriação não é efectuada.

Outro conceito que está estritamente ligado ao de espaço público é o de acessibilidade, defendido por vários autores como o lugar onde qualquer indivíduo pode circular livremente. Serpa (2004,p.22) refere que a acessibilidade

Está estreitamente vinculada, na demarcação dos territórios urbanos, à alteridade, contrapondo uma dimensão simbólica (e abstracta) à concretude física dos espaços públicos urbanos. Pois a acessibilidade não é somente física mas também simbólica (e abstracta) na concretização física dos espaços públicos urbanos.

Para este autor, a acessibilidade não é somente física, mas também simbólica, e a apropriação social dos espaços públicos urbanos tem implicações que ultrapassam o design físico de ruas, praças, parques, largos, centros comerciais e prédios públicos. Podemos dizer que a acessibilidade na visão deste autor transporta uma dimensão física e outra simbólica, mas assentes na dimensão social do espaço.

Por fim, Carreras i Verdaguer (2002) analisa o espaço público do ponto de vista da sua função. Refere que nesta acepção, os espaços podem ser especializados ou polivalentes, isto é, monofuncionais ou plurifuncionais. Os espaços públicos abertos são essencialmente polivalentes, dedicados a usos diversos, e que um uso pode predominar sobre outros; assim, as ruas e as praças, os passeios e as avenidas, os parques e os jardins servem para circular e comunicar, para passear e encontrar-se, para trabalhar e passar o tempo, para contemplar e ser contemplado. Esta definição de Carreras i Verdaguer vai muito de encontro aos princípios do modernismo, em que os espaços públicos eram construídos para a burguesia passear, ser vista, como espaços de decoração para as elites. Em contrapartida, geravam-se espaços de exclusão que, mesmo passado 
tanto tempo, se continuam a gerar nas sociedades contemporâneas. Podemos reflectir sobre o exemplo de Barcelona: hoje como o espaço é acessível a todos, criam-se grupos que geram guetos urbanos e reproduzem incertezas na vivência dos espaços, as classes médias "cultas" deixam de ir a estes espaços. Outra visão que importa ter em conta é de Jordi Borja (2003, p.1). Para este autor

O espaço público é um conceito próprio do urbanismo que às vezes se confunde com (erradamente) com espaços verdes, equipamentos ou sistema viário, mas que também é utilizado na filosofia política como lugar de representação e de expressão colectiva da sociedade.

Borja tem uma concepção de espaço público que se centra essencialmente na trilogia cidade -espaço público - cidadania. Defende que nenhum destes termos se pode entender isolado, pois "[...]a nossa vida depende em boa medida desta relação[...]" (BORJA, 2003, p.22). Explica que os valores vinculados à cidade, de liberdade e de coesão social, de protecção e desenvolvimento dos direitos individuais e de expressão e construção de identidades colectivas, de democracia participativa e de igualdade básica entre os seus habitantes, depende de que o estatuto de cidadania seja uma realidade material e não só um reconhecimento formal. No entanto, esse reconhecimento é algo de extrema dificuldade na cidade contemporânea, pois privilegiam-se valores de acumulação, alheios à vontade pública, como que uma alienação do sujeito face à produção do espaço.

$\mathrm{Na}$ realidade, a ascensão do espaço público como mote dos grandes projectos de renovação urbana, prende-se, a estratégias de promoção da cidade, baseadas no marketing, simplesmente dotado de uma formalização pontual e especifica que lhe concede o estatuto da diferença. Isto porque o urbanismo é o principal habilitado de mudança, mas inevitavelmente o principal indutor de acumulação do capital, aquele que conduz à produção de enclaves escalares3. Contrariamente ao urbanismo em que os espaços públicos são meros resquícios da urbanização, estes deveriam ser geradores de traçados, malhas e estruturas.

Assim, o capitalismo encontrou no urbanismo uma nova forma de reprodução do capital. A espacialidade dos lugares ganha uma nova dimensão, os espaços ganham uma nova configuração. Segundo Harvey (1992), Preteceille (1988), Santos (1996) e Dantas (1997), no planeamento urbano, a partir da década de 90, na matriz anterior do planeamento (regulatório), o espaço era visto como recurso a ser moldado com propósitos sociais e actualmente o espaço é entendido como dimensão independente e autónoma, a ser moldada segundo princípios estéticos. Nesta última acepção, o espaço, reificado, adquire uma posição 
aparentemente mais importante por conter a capacidade de gerar resultados em/por si.

A composição dos princípios estéticos do espaço entra no molde da competitividade global das grandes cidades e tenta a qualquer custo afirmar a sua territorialidade, quase sempre em princípios de composição do espaço urbano. A cidade perde o seu significado historicista face a estes novos processos de urbanização, os lugares ganham novas identidades, incluindo o próprio conceito de lugar, que passa a ter alguma resistência face à sua identidade, pois como refere Castells (1996), na sociedade-rede surge uma nova espacialidade, onde os espaços de fluxos predominam sobre os espaços de lugares, alterando a sua forma, função e significado. Contudo, a própria demanda da administração pública, tem sido a principal causadora, conjuntamente com os técnicos com destaque para os arquitectos, das transformações incoerentes do espaço público. A administração pública, sobretudo a local, tem uma influência muito forte na estruturação do marco físico urbano, pois actua directamente sobre o espaço urbano, seja por aprovação, aplicação e defesa dos instrumentos de gestão urbanística, seja ao lado das actuações privadas. O que se passa é que essa conectividade é conduzida através de interesses próprios e de máxima rentabilização dos mesmos. Mesmo que os instrumentos de gestão territorial vigentes aparquem actuações que visem a sustentabilidade do espaço urbano, estes muitas vezes não são aplicados.

De um modo geral podemos concluir que é difícil apresentar uma definição concreta de espaço público, pois encara diversas vertentes de abordagem que se interligam. Contudo, o espaço público é um lugar aberto, de acesso irrestrito, um ponto estruturante da malha urbana e confluência de vários caminhos e lugares, é um espaço de passagem e de permanência, construído por diversos agentes, quer na sua forma material ou vivêncial. O espaço público é uma estrutura e estratégia de forma caracterizada pelos seus elementos constituintes (que o individualizam), social e económica.

\section{As dimensões do Espaço Público: o espaço público na esfera pública urbana}

Como reiteramos, o conceito de espaço público abarca diversas dimensões algo complexas. O interesse do homem pelo espaço têm raízes existenciais, pois deriva de uma necessidade de adquirir relações vitais no ambiente que o rodeia, para dar sentido e ordem a um mundo de acontecimentos e acções (NORBERG-SHULZ, 1975). Contudo, umas das afirmações que mais aborda e demonstra o quanto o espaço público é importante, está na definição de E.Kant, retomada posteriormente por Habermas, onde se defende que o espaço público está no coração do 
funcionamento democrático. Estes popularizaram o seu uso na análise política a partir dos anos 70 . Habermas define-o como a esfera intermédia que se constituiu historicamente, no período das Luzes, entre a sociedade civil e o Estado. O espaço público é o lugar, acessível a todos os cidadãos, onde um público se reúne para formular uma opinião pública. O intercâmbio discursivo de posições racionais sobre problemas de interesse geral permite identificar uma opinião pública. Esta «publicidade» é um meio de pressão à disposição dos cidadãos para conter o poder do Estado. Mas Habermas (1984) considera que o aparecimento do EstadoProvidência perverteu esse mecanismo de concertação democrática. Tal como outros, procuro pelo contrário, caracterizar e compreender o papel do espaço público numa democracia de massas. Quer dizer, um espaço muito mais vasto do que antes, com um número muito maior de temas debatidos, um número muito maior de agentes intervindo publicamente, uma omnipresença da informação, das sondagens, do marketing e da comunicação.

O espaço público é o espaço da sociedade, o espaço político como refere Hannah Arendth (1972) e nestes contornos é necessariamente um espaço simbólico, pois opõem-se e respondem-se a discursos, dos agentes políticos, sociais, religiosos, culturais, intelectuais que constituem uma sociedade. É, portanto, antes de mais, um espaço simbólico, que requer tempo para se formar, um vocabulário e valores comuns, um reconhecimento mútuo das legitimidades; uma visão suficientemente próxima das coisas para discutir, contrapor, deliberar. Não se decreta a existência de um espaço público da mesma maneira que se organiza eleições. Constata-se a sua existência. O espaço público não é da ordem da vontade. Simboliza, simplesmente, a realidade de uma democracia em acção, ou a expressão contraditória das informações, das opiniões, dos interesses e das ideologias.

Numa perspectiva territorial e tecnicista, o espaço público é, à partida, um espaço físico; o da rua, da praça, do comércio e das trocas. É o espaço que a "olho nú" qualquer um identifica por características formais que o individualizam.

O espaço público é, evidentemente, a condição para o nascimento do espaço político. A ideia de que as cidades possuem uma esfera pública, pertencente e usada pela colectividade, e uma esfera privada, cuja posse e manutenção respondem aos interesses de um ou mais indivíduos específicos, é bastante antiga, mas virá a definir-se plenamente com a urbanística grega durante a Antiguidade Clássica. Para os gregos, aagora era o espaço que, inserido na polis, representava o espírito público desejado pela colectividade e onde se exercia a cidadania.

A definição clara do limite entre os espaços públicos e privados, porém, perdeu-se em vários momentos na história, contrariamente ao que se pensa que é uma coisa da sociedade contemporânea, talvez agora seja 
mais vinculado face a demandas tão flexíveis num espaço-tempo muito curto. As cidades europeias medievais construíram-se através de uma constante apropriação da terra pública e da definição desordenada de ruas, normalmente estreitas e insalubres. Tal situação repetiu-se, grosso modo, até ao aparecimento do urbanismo sanitarista no século XIX, através das intervenções de Hausmann em Paris e de Ildelfonso Cerdá em Barcelona. Ainda que baseados num discurso muito mais estatal que público, estas intervenções colocaram o desenho das áreas públicas (especialmente as grandes avenidas) como prioritárias na definição da paisagem urbana.

O Movimento Moderno (início do século XX) representou uma releitura da ideia de público. Segundo vários representantes, todo o solo dentro dos perímetros urbanos deveria ser de propriedade pública, sendo pertencentes à esfera privada apenas fracções ideais destes terrenos correspondentes aos apartamentos particulares. Esta ideia foi pouco posta em prática, sendo considerada por diversos críticos como "ingenuamente utópica". Diversos teóricos, entre os quais se destaca Jane Jacobs, no seu livro Morte e Vida das Grandes Cidades, criticaram as propostas modernas e sua aplicação na cidade real. Todo este conjunto de críticas gerou nas últimas décadas uma grande valorização da rua como o espaço público essencial às cidades. Talvez os princípios defendidos por esta autora sejam de facto demasiadamente utópicos e pouco realistas, mas o facto é que se denotou um maior interesse pela problemática.

Mais tarde, o Novo Urbanismo, vulgarmente conhecido como o urbanismo do espaço público, veio modificar as linhas orientadoras de intervenção do espaço público. O modo de projectar o espaço organiza-se sobretudo em torno a elementos formais, onde o processo cognitivo assume as linhas base de intervenção. Contudo, o novo urbanismo vai permitir o aumento da densidade, o uso múltiplo (comércio e residência), como forma de diminuir a degradação ambiental e promover mais interacções de vizinhança e diminuir a dependência do automóvel. O aumento da densidade salva áreas de cultivo e reservas naturais da ameaça do modelo suburbano, assim como agrada à indústria da construção, que vende mais cidades em menor espaço. Este processo fez com que aumentasse o número de condomínios fechados, a gentrificação, conservadorismo estilístico, homogeneidade e uma imagem geral de intolerância.

As políticas públicas e os desafios do território impõem novas estruturas político-admínistrativas, mas as indolências são muito fortes e em geral as reestruturações paralisam-se antes de serem implementadas ou então produzem um abismo de eficaz inflação institucional. Necessariamente que ao nível do urbanismo isto tem repercussões, pois o tempo de construção da cidade é distinto do tempo de aplicabilidade e reflexo dos instrumentos de gestão territorial. E considerando as conduções que se elevam às novas produções urbanísticas, a equitabilidade do espaço 
urbano regenera-se de forma diferenciada e descontínua. A reprodução da forma eleva-se necessariamente a uma monumentalidade dos espaços, em que importa a diferenciação e a capacitação de aludir à sua passagem, que não se prende com vivência e muitas vezes se traduz num aniquilamento do seu lugar. Da mesma forma que o urbanismo e as políticas de intervenção têm a capacidade de regenerar, também têm a capacidade de destruir. Por isso é importante discutir a problemática historial do urbanismo e das suas reproduções face às novas demandas territoriais.

\section{A forma e a apropriação do espaço público}

$\mathrm{Na}$ conceptualização da forma, podemos num primeiro momento, explicitar a concepção de Platão e Aristóteles, que concebem o espaço e a matéria como sendo inseparáveis e a geometria o seu elo abstracto de ligação. O espaço tem uma forma que se transpõe através das linhas geométricas, configurado através de um desenho que o concretiza e transforma num "espaço". Se pensarmos a cidade, esta é celebrada através das linhas que a constituem, linhas que podem ser planas, dimensionais ou tridimensionais, mas que no todo a encerra, a formaliza e a identifica. Contudo, esta percepção de que a forma individualiza a cidade é algo recente. Lefebvre (1973) caracteriza a forma urbana a dois níveis de abordagem, na dimensão mental e na dimensão social. Na primeira caracteriza a forma como a simultaneidade (de acontecimentos, percepções, elementos de um conjunto no real). Em termos sociais, caracteriza a mesma como o encontro e a conjunção do que existe nos arredores, no meio (bens e produtos, actos e actividades, riquezas) e, por conseguinte, a sociedade urbana como lugar socialmente privilegiado, como sentido de actividade (produtoras e consumidoras), como encontro de obra e produto. A caracterização de Lefebvre (1973) remete para o projecto de espaço público, uma vez que este é necessariamente uma obra produzida segundo determinados interesses que se transforma num produto, pois destina-se ao consumo por aqueles que dele se vão apropriar. Enquanto produto, a forma é determinada pelo tecido territorial em que é produzida, ou seja, marca necessariamente um contexto social, político e económico, contém uma história. A forma não é involuntária, mas sim repleta de significados e aspirações, até porque, mesmo que se tenha diluído, a percepção é que esta se faz para os cidadãos, esta “[...]constitui uma função primordial de sociabilização, centrada em eixos determinantes que se sobrepõem a um princípio fundamental[...]" (ROBIRA, 2002, p. 117). A forma do espaço público tem muito a ver implicitamente com o momento histórico em que é definido, mas nem sempre um espaço público coincide com um único período histórico. As 
ruas, as praças ou os parques têm um sentido ou outro ao longo dos tempos, e merece uma especial atenção no momento de intervenção. Em cada projecto deve-se encontrar sempre um conceito.

A forma compreende diversos significados, é constituída (ou deveria ser) pelas representações espaciais, sociais e políticas do contexto que a reproduz. Individualiza e marca determinada territorialidade através de elementos que a compõem. A forma do espaço público pode ser analisada a diversas escalas. Podemos considerar desde a forma de um canteiro de plantas, à forma total de um espaço (podemos exemplificar ao nível de uma praça) até à forma desse espaço dentro do seu contexto territorial (cidade). Contudo, a forma de um espaço está muito ligada à sua função, apesar do Arquitecto Albert Viaplana4 considerar que a função não existe, somente a forma se impõe na criação do espaço, da obra. No entanto, esta consideração nem sempre foi assumida pelos urbanistas e planeadores do espaço público, sobretudo nos princípios do urbanismo racionalista, em que a função impera sobre a forma. Como refere Ribeiro (2000, p.4-5)“[...]as linhas implícitas na modernidade podem silenciar vozes, valores e argumentações alternativas, impondo uma unidade monológica sobre toda a sociedade".

Deste modo, segundo Magalhães (2001, p.223)

A função de uso e a função ecológica passaram a constituir os dois
principais pressupostos da concepção da paisagem, ambos com
fortes repercussões na sua forma. As funções de uso são o ponto
de partida para chegar à forma. O espaço era dividido num
zonamento destinado às funções, impostas pelo programa ou
determinadas pela aptidão ecológica, e a forma surgia a partir
desse zonamento, para dar resposta às funções de uso.

Porém, a evolução do conceito de espaço público que tem ganho cada vez mais novas abordagens, moldadas através da evolução na produção do espaço urbano, marca inicialmente uma virada na concepção da forma dos espaços. Actualmente a produção do espaço público5 atribui um significado primordial à forma, efectivada por novas demandas sociais, produzida através de novas condutas, que segundo Costa \& Pereira (2004) emergem, fruto da globalização da economia e dos avanços tecnológicos, que resultam das confluências dos decursos económicos, políticos e sociais. Estes são consequência de processos dinâmicos e dialécticos, e assim consideradas construções efémeras que se dissolvem com a acção do mercado e que se materializam nas cidades. Os dispositivos de controlo, cada vez mais subtis e menos evidentes, activam este conjunto de princípios, que permeiam por todos os cantos, desfiguram o "novo" e influenciam as estruturas sociais. As nossas acções e pensamentos modelam o espaço, mas, ao mesmo tempo, os espaços mais amplos colectiva ou socialmente produzidos nos quais vivemos também modelam as nossas acções e pensamentos (SOJ A, 1993). 
Para Santos (1986), a ideia central da interpretação da produção do espaço situa-se na combinação simultânea entre a forma, a estrutura e a função. Isso porque "[...]os movimentos da totalidade social, modificando as relações entre os componentes da sociedade, alteram processos e incitam funções" (SANTOS, 1986, p.38). Na concepção deste autor, essa totalidade social, pressupõe a existência de um movimento dialéctico da estrutura que opera sobre as formas e funções, fazendo com que os lugares se tornem combinações de variáveis que se diferenciam ao longo do tempo. Essa estrutura é formalizada através dos espaços e porque este é a sociedade em que cada fracção da natureza abriga uma fracção da sociedade actual. Assim temos, por uma parte, um conjunto de objectos geográficos distribuídos sobre um território, a sua configuração geográfica ou a sua configuração espacial, e o modo como esses objectos mostramse perante os nossos olhos, na sua continuidade visível, isto é, a paisagem; por outro lado, o que da vida a esses objectos, o seu principio activo, ou seja, todos os processos sociais representativos de uma sociedade num dado momento (SANTOS, 1986).

Deste modo como refere o autor estes processos plenos de funções realizam-se através das formas. Não sendo originalmente formas geográficas, acabam no entanto por ter uma expressão territorial, pois, sem as formas, a sociedade, através das funções e dos processos, não se realizaria.

Daí a importância prestada a uma nova condução na estruturação formal do espaço público. Como refere Brandão Alves (2003, p. 297) "o espaço público fantástico é aquele que capta o olhar e amplia a imaginação". Se considerarmos o período romântico, sempre houve um eclodir de princípios formais voltados para o simbolismo do "paraíso perdido", um pouco desfasados pelo modernismo que atribui a estes espaços funções meramente utilitárias. No caso, estes baseavam-se nos fundamentos ecológicos da natureza, que começam a integrar os princípios de intervenção na cidade, e a constituir o "centro" do desenvolvimento do desenho urbano. Contudo, ambas as dimensões estão muito interligadas. Vejamos a abordagem de Lynch (1980, p.103):

Uma cidade é uma organização mutável com fins variados, um conjunto com muitas funções criado por muitos, de um modo relativamente rápido. Uma especialização total, uma engrenagem perfeita são improváveis e indesejáveis. A forma tem, de certo modo, que ser não comprometedora, moldável aos propósitos e às percepções dos cidadãos. Existem, contudo, funções fundamentais que podem ser expressas pelas formas de uma cidade: circulação, aproveitamento dos espaços mais importantes, pontos-chave focais. As esperanças e satisfações comuns podem ser humanizadas. Sobretudo se o ambiente está visivelmente organizado e nitidamente identificado, poderá então o habitante dá-lo a conhecer, por meio dos seus próprios significados e 
relações. Nesse momento tornar-se-á um verdadeiro lugar notável e inconfundível.

Na concepção de Lynch (1980), a forma do espaço denota de momento a sua apropriação, pois existe uma relação recíproca que determina o espaço. Isto porque se houver uma "[...]apropriacion continua y dinâmica del espacio da al sujeto una proyección en el tiempo y garantiza la estabilidad de su própria identidad[...]"(POL,1996, p.14). Assim, os espaços, os objectos e as coisas ganham um significado através dos usos e do tempo. O mesmo autor segue aludindo que a forma dos espaços tem forte influência na sua apropriação, mesmo que esta seja (POL, 1996, p. 15)

\footnotetext{
"[...]un proceso espontáneo, natural, aunque intencional en alguna medida, las características del espacio, su rigidez o flexibilidad, su contraposicion o sintonizacion com el colectivo usufructuario, pueden ser factores facilitadores o dificultadores".
}

Genericamente, apropriação é o acto segundo o qual um sujeito toma posse de algo que não Ihe pertencia e o torna próprio. Do mesmo modo, o acto de enunciar implica um processo de apropriação da língua em que o locutor/anunciante constrói um universo de referência discursiva que é parte integrante da enunciação. O anunciar pode ser encarado através da apropriação como a expressão dos grupos que através da forma conduzem o seu comportamento no espaço público pela identificação6 com o mesmo. E neste sentido, retomando Milton Santos (1986), entramos no que o autor define de forma-conteúdo, pois o seu significado é variável na medida que o movimento social lhes atribui em cada momento, fracções diferentes do todo social. "Puede decirse que la forma, en su cualidad de forma - contenido, está siendo permanentemente alterada, y que el contenido adquiere una nueva dimensión al encajarse en la forma."(SANTOS, 1986, p.42). Este processo define também o processo histórico e social da cidade. Deste modo, será que podemos afirmar que a forma do ponto de vista organizacional, gera ou afirma o modelo político da estrutura territorial vigente?

A apropriação envolve necessariamente a interacção recíproca utente/espaço, na qual o utente age no sentido de moldar os lugares segundo suas necessidades e desejos e o seu contexto social. Os lugares, em contrapartida, tornam-se receptivos. Essa influência mútua entre utente/espaço é a razão pela qual as pessoas e os grupos encontram, ou não, sua identidade nos diversos lugares em que vivem.

Além destes aspectos subjectivos, a ambiência também engloba aspectos objectivos, que interferem com as sensações corpóreas que se experimentam num lugar. Enquanto os aspectos subjectivos são activados pela maneira em que os materiais, as cores, as texturas e as formas são combinadas para compor o ambiente, os aspectos objectivos são activados pelas condições térmicas, acústicas, luminosas e dimensionais. 
Ambos têm consequências comportamentais. A principal diferença entre eles está no facto de que os primeiros se encontram ligados à cultura, enquanto os demais são inerentes à condição humana. Se uma pessoa está sentindo muito frio ou calor ela não se sentirá confortável, por mais bonito e atraente que seja o lugar onde estiver. Isto acontece porque o corpo humano deve manter uma temperatura interna constante e, por isso responde às condições térmicas de modo a manter o equilíbrio entre a quantidade de calor produzida pelo processo metabólico e a quantidade de calor consumida no ambiente. A dimensão física da ambiência pode ser entendida como a necessidade que se tem de viver em harmonia biológica com o ambiente, bem protegido contra as tempestades e em situação de conforto relativamente à postura do corpo.

Ao nível da arquitectura, a ambiência tem duas dimensões, uma subjectiva, que se encontra na relação afectiva das pessoas com os objectos funcionais e outra objectiva, de carácter fisiológico, que existe nos estados de conforto que as pessoas experimentam no ambiente construído, na sua relação com os objectos. A dimensão subjectiva está relacionada com o sistema de significados dos objectos e depende dos modelos culturais predominantes num grupo. A subjectividade da ambiência é um fenómeno que se revela através dos usos, dos costumes e da moda e actua na estruturação do sistema dos objectos funcionais, conferindo um determinado carácter à distribuição espacial desses objectos. Segundo Malard (2007), a ambiência revela-se no quotidiano, em qualquer interacção utente/espaço, independentemente de factores sociais ou económicos. Neste sentido, após a análise do objecto de estudo, esta afirmação não me parece totalmente correcta, pois aquilo que na prática se observa é que os factores sociais e económicos tem igualmente um peso importante na forma como as pessoas vivem os espaços e deles se apropriam. Pode-se dizer então que a ambiência é revelada no processo de apropriação do espaço. A dimensão objectiva da ambiência diz respeito às sensações corpóreas que são experimentadas na interacção usuário/espaço/objectos. A objectividade da ambiência é também absorvida de subjectividade, uma vez que não se pode separar o objecto/símbolo do objecto/signo quando se trata de analisá-lo no contexto do uso (MALARD, 2007). Assim, a qualidade do ambiente urbano construído, à parte de conter na sua projecção uma ambiência própria, é reconstruída pelas vivências que nele se reproduzem. $\mathrm{Na}$ /pela forma do espaço construído, o ser humano pode-se identificar e apropriar-se do mesmo, de acordo com a sua envolvente territorial.

Ao nível da arquitectura, a forma é a aparência sensível das coisas e a forma artística é a que surge das mãos do criador. No processo de criação, a forma une-se à matéria sem a qual a primeira não existia. As formas arquitectónicas constituem como as pictóricas e escultoras, uma linguagem própria que pode transmitir mensagens. Em termos da 
arquitectura, os elementos formais básicos da sua linguagem são a coluna, o pilar, o arco, a abobada, os capitéis, e os marcos. Todos estes elementos formam parte de sistemas construtivos específicos, que necessariamente traduzem uma linguagem concreta. Ao modo como cada uma destas linguagens se articulam e se aplicam, pode-se chamar de estilo. As formas físicas determinadas pela arquitectura, assim como por todas as artes plásticas reproduzem-se em diferentes materiais. São formas puras, não figurativas, que detêm um determinado efeito psicológico, pelas suas qualidades expressivas. A forma é o princípio de construção do espaço, ela constrói o lugar e a sociedade. Segundo Arnheim (1978, p.24), que defende o formalismo" [...] la forma puede ser desdeñada, pero no es posible prescindir de ella". A abordagem do arquitecto Brandão Alves (2003) expressa bem o significado da forma no contexto do espaço público, pois a sua existência tem uma configuração que o caracteriza e individualiza, transformando-o num lugar único. Se considerarmos a inserção de Enric Pol (1996) na apropriação dos espaços é congruente afirmarmos a importância que o desenho tem na concepção do espaço, pois o desenho é determinante na sua apropriação. Contudo, a forma do espaço também se individualiza através da sua tipologia, que direcciona a sua vivência. Essas tipologias, concretizam-se em espaços de circulação (como a rua ou a praça), espaços de lazer e recreação (como uma praça ou parque urbano), de contemplação (como um jardim público) ou de preservação ou conservação (como um grande parque ou mesmo uma reserva ecológica). A forma é transposta ao espaço através do desenho, que segundo as suas linhas, define a tipologia de espaço. Assim, a importância do desenho urbano, objectiva a máxima generalização e estabilidade formal no desenho dos elementos urbanos. Procurar a estabilidade formal e a generalização não são condições suficientes para garantir a qualidade de um desenho, esta comporta uma certa renúncia a atitudes experimentais ou de moda. É importante definir critérios que descrevam as relações entre os elementos que formam o discurso urbano e as regras que determinam estas relações. Acostumados à super posição, a qualidade individualizada dos desenhos não garantem o equilíbrio do espaço urbano. Neste sentido é importante a coordenação dos diferentes serviços públicos e administração municipal que intervêm no espaço urbano. Muitas vezes os projectos não conseguem dar reposta às necessidades urbanas, porque os projectistas encaram o desenho do espaço público de forma fechada, como um produto acabado, que não vive o tempo da cidade nem o tempo de interpretação dos seus usuários. Considerando a tipologia de praça, como uma unidade morfológica cujas características e importância no seio da cidade melhor ilustram a sua génese conceptual, constatamos a importância do desenho da mesma na cidade. Uma praça já não é somente o finalizar de uma rua delimitada por edifícios, se não um conceito que admite mais espaços ambíguos, sem 
contornos imediatos, pois o que a caracteriza como praça já não é somente a sua forma ou função, se não o seu objectivo de constituir-se num lugar. Um lugar tem que ter uma estrutura que se define através do desenho e do modo como as pessoas se apropriam dele. A praça reúne a ênfase do desenho urbano como espaço colectivo de significação importante. Este é um dos seus atributos principais e que a distingue dos outros vazios da estrutura das cidades (LAMAS, 1992). O desenho do projecto tem assegurado as grandes composições urbanas ao nível do espaço público, o que tem determinado imagens e identidades. Houve uma evolução morfológica e funcional no desenho das praças tradicionais, até aos dias de hoje. Actualmente estas são concebidas com um uso muito específico, cuja função do desenho tem sido a de criar um espaço de reunião agradável e conseguir caracterizar zonas descuidadas ou degradadas das cidades. Por isso, os principais problemas das componentes que constituem os espaços públicos e definem a sua tipologia prendem-se com a sua distribuição, disposição e configuração, e tem sido isto que tem gerado um empobrecimento do espaço público agravado pelo surgimento de novos espaços públicos privados. A praça como espaço de discussão da vida pública, enfraqueceu, pois o aceleramento dos processos de produção e reprodução do espaço, promovidos pela globalização, tendem a um fim da esfera pública, devido ao enfraquecimento do Estado - nação e da conjuntura entre o sector público e privado. As praças são lugares muito importantes para a cidade, a cidadania, mesmo, e sobretudo perante a globalização (SANTOS, 2000). A praça é um espaço voltado essencialmente ao encontro no âmbito da esfera da vida pública, não é apenas forma ou paisagem, é um cenário e palco para as acções da vida pública.

A envolvente dos espaços públicos, a distribuição funcional das superfícies e o tratamento do solo, a vegetação, o mobiliário urbano, os serviços e instalações, os elementos de informação, a iluminação, os elementos arquitectónicos isolados e as passagens e passadiços são os problemas específicos apontados por Brandão Alves (2003). A reversão destes problemas, prende-se com uma nova linguagem geométrica que assenta em factores de ordem social, pois o conceito de intervenção deve surgir da história que envolve o espaço, uma vez que este é o elemento ordenador no desenho urbano e o reforço da ligação do homem ao lugar.

\section{Constituição do Lugar}

A expressão lugar deriva do latim locus. Ao nível da geografia, o conceito de lugar tem sido alvo de vários estudos, que segundo Adriana Leite (1998) constitui num dos seus conceitos-chave. De acordo com esta autora é possível identificar duas acepções principais no conceito: o da 
Geografia Humanística e o da Dialéctica Marxista. Embora estas correntes possuam fundamentações filosóficas diferenciadas, têm em comum o facto de terem surgido como reacções ao positivismo então vigente, o qual permite a descrição da natureza a partir da dissociação Homem-Meio. A corrente humanista define o lugar como sendo um produto da experiência humana, que significa muito mais que o sentido geográfico de localização. Não se refere somente a objectos e atributos das localizações, mas a modelos de experiência e envolvimento com o mundo, a necessidade de raízes e segurança (RELPH, 1979). Ou ainda, como sendo um centro de significados construído pela experiência (TUAN, 1975) e pelas relações de afectividade que podemos desenvolver ao longo de nossa vida com o mesmo. Os lugares estão cheios de sensações emotivas, principalmente porque nos sentimos seguros e protegidos (MELLO, 1990). O lugar encerra sobre si mesmo uma dimensão simbólica, emotiva, cultural, biológica, política e social de acordo com o que cada indivíduo espera do mesmo.

Os lugares só adquirem identidade e significado através da intenção humana e da relação entre as intenções e os atributos objectivos do lugar, ou seja, o cenário físico e as actividades ali desenvolvidas (RELPH, 1979). O lugar é criado pelos seres humanos para os propósitos humanos (TUAN, 1975). O autor afirma que há ainda uma estreita relação entre experiência e tempo, na medida em que o sentido de lugar raramente é adquirido pelo simples acto de passarmos por ele. No caso, seria muito importante um período de tempo de ligação com o lugar, que se prende necessariamente com a apropriação do mesmo, tem que haver um envolvimento. No entanto, seria possível a um indivíduo apaixonar-se à primeira vista por um lugar da mesma forma que o faz por uma pessoa (TUAN, 1983). Em contraste, uma pessoa pode ter vivido durante toda a sua vida em determinado lugar e a sua relação com ele ser completamente irreal, sem nenhum enraizamento. O lugar pode ser também uma imposição, em que um indivíduo não tem escolha e é obrigado a viver o lugar.

A experiência do lugar manifesta-se também a diferentes escalas, pois depende dos diferentes espaços que vivemos, que podem ir do quarto da habitação, à igreja ou a um jardim. Os lugares normalmente não são dotados de limites reconhecíveis no mundo concreto, porque são uma construção aparente e ao mesmo tempo tão incorporada às práticas do quotidiano, que as pessoas que os vivem não o percebem como tal. Este juízo de valor só se manifesta na consciência quando há uma ameaça ao lugar. Assim, ao contrário das regiões delimitadas para fins de planeamento, plenamente reconhecíveis em mapas e cartas topográficas, através de símbolos e toponímias, a maioria dos lugares não são nomeados, ou melhor apenas o são através da forma e da relação que mantêm com o mesmo. Assim, segundo Tuan (1975) dar nome a um lugar é reconhece-lo, isto é, identificar conscientemente ao nível da 
verbalização, facto este que não ocorre na realidade. Apesar da intensidade das experiências vividas a nível do país, da cidade, do bairro, ou da rua, se fossem representados cartograficamente, tais lugares seriam menores que sementes, mas ainda assim germinariam afeição. No entanto, tais relações de identidade não limitadas fisicamente através do desenho, nem sempre são respeitadas ao nível dos interesses políticos.

Considerando os diferentes graus de compreensão da realidade apresentados pelos indivíduos, Relph (1976) desenvolveu duas classes de percepção dialéctica Homem - Meio: uma a partir da perspectiva interna daquele que vive o lugar e outra a partir da perspectiva externa. Para cada perspectiva assumiu que haveria níveis intermediários de percepção, variando entre o mais enraizado e o mais desenraizado.

Outra abordagem da relação Homem-Meio foi realizada por Mello (1990), tendo como base as obras de Tuan (1983) e de Relph (1976). Mello (1990) identifica três conceitos principais: o lugar como resultado da experiência sendo assim um "[...]mundo ordenado e com significado" (TUAN, 1983, p.65); o lugar como um conceito " [...]fechado, íntimo e humanizado" (TUAN, 1983, p.61); e o último conceito seria o de "deslugar" (placelessness), um neologismo criado por Relph para designar formas repetidas e de sequências uniforme, como por exemplo os conjuntos habitacionais. Este conceito tem sido alvo de muitas discussões no âmbito da Geografia Humana, pois questiona-se se as pessoas que realmente o experimentam o consideram monótono e artificial. Neste sentido, Relph introduz uma discussão a respeito de atitudes autênticas e inautênticas em relação ao lugar. As atitudes autênticas seriam aquelas em que o indivíduo teria plena consciência do teor ideológico encaixado naquelas formas. Por outro lado, uma atitude inautêntica caracterizaria uma visão alienada do lugar e a relação Homem-mundo vivido não seria plena. Exemplo dessa alienação é as formas tipificadas de consumo como os centros comerciais e franquias de restaurantes. Eyles (1989, p.109) analisa criticamente essa percepção sugerindo que "[...]as tendências homogéneas do mundo moderno resultam para a grande maioria das pessoas, numa atitude "inautêntica" em relação ao lugar e num estado de "deslugar". Para ele, há um profundo descrédito relativamente à capacidade que as pessoas têm em criar identidade com os lugares, apesar de serem formas homogéneas. 0 conceito de deslugar encontra algumas similitudes com o conceito de nãolugar de Marc Augé (2005), pois se para este autor um lugar se pode definir como identitário, relacional e histórico, um espaço que não pode definir-se nem como identitário, nem como residencial, nem como histórico, definirá um não-lugar. São espaços sem identidade, sem relação, que criam solidão e semelhança pelas formas homogeneizadas. 


\section{Lugar e Forma}

Outro conceito de lugar diz respeito à sua compreensão enquanto expressão geográfica da singularidade, descentrada, universalista, objectiva, associada ao Marxismo. Trata-se de uma visão em que o lugar é considerado tanto como produto de uma dinâmica que é única, resultante de características históricas e culturais intrínsecas ao seu processo de formação, como uma expressão da globalidade. Neste sentido, o lugar apresenta-se como “[...]o ponto de articulação entre a mundialidade em constituição e o local, enquanto especificidade concreta e momento" (CARLOS, 1996, p.16). A origem desta percepção encontrase relacionada com o processo de expansão dos modos capitalista de produção que através de uma ampla rede de fluxos (de transportes, informação e mercadorias), conseguiu incorporar progressivamente todos os pontos da superfície do planeta, inclusive os mais remotos. A descoberta de novos territórios a partir das grandes navegações propiciou a ampliação dos conhecimentos em relação ao globo, indicando simultaneamente que este era finito e potencialmente apreensível. De acordo com Harvey (1992, p.221)

A acumulação de riqueza, de poder e de capital passou a ter um vínculo com o conhecimento personalizado do espaço e o domínio individual do mesmo. Do mesmo modo, todos os lugares ficaram vulneráveis à influência directa do mundo mais amplo graças ao comércio, à competição intra-territorial, à acção militar, ao influxo de novas mercadorias, ao ouro e à prata etc.

Este foi um reflexo directo do aperfeiçoamento das técnicas de produção e das redes de transporte e comunicação. Considerando que as contradições internas se constituem na principal razão de existência do capitalismo, o lugar, segundo este ponto de vista, seria também um reflexo desta ambiguidade, e das dualidades centro/periferia, geral/particular, globalização (homogeneização) /fragmentação. Segundo Harvey (1992, p.231)

A necessidade de um novo modelo de gestão do território que fosse eficiente em propiciar o bem-estar social e este, por sua vez, dentro dos princípios da igualdade, encontrou na homogeneização do espaço o único meio de exercer sobre ele o controle, e logo de alcançar tais objectivos.

Houve neste momento um grande desenvolvimento da cartografia matemática que, contrariamente às práticas comuns à Idade Média, passou a projectar nos mapas um espaço abstracto, homogéneo e universal nas suas qualidades, propiciando assim um quadro de pensamento e de acção estável e apreensível (HARVEY, 1992). Esta nova forma de entender a realidade motivou diversos técnicos, assim como administradores e proprietários de terras. Sentiu-se a necessidade de consolidar o uso do espaço (homogéneo, abstracto e universal). Para tal 
deu-se a organização da propriedade privada e a compra e venda do espaço como mercadoria, instituindo-se a fragmentação do espaço. De facto, como afirma Lefebvre (1973), uma das formas de se alcançar a homogeneização do espaço é justamente através de sua fragmentação em parcelas livremente alienáveis de propriedade privada, que podem ser compradas e comercializadas à vontade no mercado.

O lugar surge como uma expressão do processo de homogeneização do espaço imposta pela globalização, enquanto expressão da singularidade, na medida em que cada lugar exerce uma função imposta pela divisão internacional do trabalho. Nas palavras de Carlos (1996:17):

A realidade do mundo moderno reproduz-se em diferentes níveis, no lugar encontramos as mesmas determinações da totalidade sem com isso se eliminar as particularidades, pois cada sociedade produz seu espaço, determina os ritmos da vida, os modos de apropriação expressando sua função social, seus projectos e desejos.

O lugar surge como produto de ambiguidade que se estende a todas as relações sociais que envolvem o homem e o meio. Para Milton Santos (1996, p. 34) "[...]quanto mais os lugares se mundializam, mais se tornam singulares e específicos, isto é, únicos". Assim, o lugar seria resultado directo da especialização desenfreada dos elementos do espaço - homens, firmas, instituições, ambiente, assim como da: “[...] dissociação sempre crescente dos processos necessários a uma maior acumulação de capital, da multiplicação das acções que fazem do espaço um campo de forças multidireccionais e multicomplexas[...]"(SANTOS, 1996, p.34). Carlos (1996) acrescenta ainda uma dimensão histórica na concepção do lugar. Esta diz respeito à prática quotidiana, ou seja, às concepções que surgem do plano do vivido, e neste sentido é bastante similar à visão humanista. Para esta autora, pensar o lugar significa pensar a história particular (de cada lugar), se desenvolvendo, ou melhor, se realizando em função de uma cultura/tradição/língua/hábitos que lhe são próprios, construídos ao longo da história e o que vem de fora, isto é, que se vai construindo e se impondo como consequência do processo de constituição do mundial.

Apesar das peculiaridades inerentes a cada lugar, estes encontram-se profundamente interligados, pois ao mesmo tempo em que a singularidade garante configurações únicas, os lugares estão em interacção, graças à actuação das forças motrizes do modo de acumulação hegemonicamente universal (o capitalismo) (SANTOS, 1996). De facto, esta é uma realidade do mundo moderno, onde uma intensa rede de fluxos (de mercadorias, informações, etc.) marca a conexão entre lugares. “Tais redes caracterizam-se por apresentar uma estrutura extremamente complexa, organizada de acordo com a especialidade de funções e segundo uma hierarquia de actividades" (CORRÊA, 1997, p.108). Esta complexidade está também na essência das relações centro-periferia, na medida em que é um dos mecanismos pelos quais tais relações são 
perpetuadas e as diferenças aprofundadas. As cidades globais (sedes das grandes corporações), na qualidade de epicentros de numerosas redes, têm promovido a organização do espaço de modo a torná-lo cada vez mais fragmentado e globalizado (CORRÊA, 1997), o que pressupõe o encerramento das diferenças entre dominadores e dominados. Saskia Sassen (1991) oferece uma argumentação interessante para a importância do lugar no contexto da globalização. Para esta autora, o lugar é essencial para a circulação de pessoas e capital que constitui a globalização, e a atenção aos lugares urbanos num mundo globalizante leva consigo o reconhecimento de que a importância da economia nacional vai diminuindo com rapidez, uma vez que, por outro lado, se insiste que a globalização tem lugar através de conjuntos sociais e económicos específicos, enraizados em lugares específicos. O lugar pode ser definido a partir desses entrelaçamentos impostos pela divisão espacial do trabalho posto que é articulado e determinado pela totalidade espacial (CARLOS, 1996). A intensa especialização das funções, aliada ao aprimoramento tecnológico, tem causado sérios impactos ao nível do lugar, principalmente no que diz respeito à libertação de enormes contingentes de mão-de-obra. Um espaço público tem que ter o seu próprio sentido de lugar. A sua forma tem que ser efectivada através da sua morfologia espacial. Assim, o espaço adquire um determinado valor.

A nível local, cada lugar vai reagir de uma maneira própria, a partir de condições pré-existentes. Pode-se dizer também, neste sentido, que o lugar, com suas características locais e globais, é um reflexo da compressão espaço-tempo. Se por um lado, as redes de fluxos diminuem as distâncias, por outro, a velocidade em que se processam tais fluxos tende quase extinguir o tempo. Para Harvey (1992, p.190) “[...] o progresso implica a conquista do espaço, o derrubamento de todas as barreiras espaciais e a aniquilação última do espaço através do tempo". Essa aniquilação é contraditória, na medida em que "[...]o espaço só pode ser conquistado por meio da produção do espaço" (HARVEY, 1992, p.234). Isto porque o espaço tanto é o palco onde se desenvolvem as relações sociais, como o local de assentamento dos meios de vida, transportes e comunicação.

Esta dinâmica ganha expressividade no espaço através dos processos de "destruição criativa". Tais processos, aliados aos constantes efeitos das redes de fluxos e logo da compressão espaço-tempo, trazem para o lugar um efeito que o define enquanto expressão da singularidade: a sua constante reestruturação como uma resultante das constantes transformações históricas. Assim podemos afirmar que o lugar representa muito mais que um espaço, que uma parcela delimitada, uma configuração territorial com determinada espacialidade.

El lugar es un conjunto de objetos que tienen autonomía de existencia por las cosas que lo forman - calles, edificios, canalizaciones, industrias, 
empresas, restaurantes, electrificación, pavimentaciones - pero que no tienen autonomía de significados, pues cada día nuevas funciones sustituyen las antiguas, nuevas funciones que se imponen y se ejercen (SANTOS, 1996, p.51).

Segundo Norberg-Schulz (1975), os espaços recebem a sua essência dos lugares e não dos espaços, a relação do homem com os lugares e através deles, com os espaços, consiste na residência. Somente quando somos capazes de residir podemos construir. A residência é a propriedade essencial da existência. Quando nos apropriamos do espaço, deteremos nele um lugar de nossa própria identidade.

Ao nível da arquitectura paisagista o lugar ganha novos significados, pois prende-se com expressões que se produzem através de objectos de elevado significado. Ao nível da ciência geográfica esta tende a ser cada vez mais "[...]a ciência dos lugares criados ou reformados para atender determinadas funções, ainda que a forma como os homens se circunscrevem nessa configuração territorial está ligada, inseparavelmente, à história do presente" (SANTOS,1996, p.51)

Os lugares resultam das dinâmicas criadas pela relação biunívoca entre o homem e o seu ambiente construído, podendo ser observado através da transformação nas formas de consumo dos espaços, pois o ser humano actua de acordo com a sua envolvente e as suas barreiras físicas, económicas ou sociais.

A forma como o homem se apropriou do espaço e como conduziu a sua vivência, transformou o lugar determinado pelas características em espaços identitários, pois, como refere Carlos (1996, p.67),

[...] lugares são dotados de uma realidade físico-sensivel, que corresponde a um uso do espaço, logo a uma prática sócio-espacial na medida em que permite acções, ora sugerindo, ora impedindo, e na sua realização produzem diferenciações.

Esta afirmação eleva-se ao "espírito do lugar", pois o respeito por este é assumido na construção da cidade, que transpõe para esta, elementos exteriores resultantes da sua interpretação. Magalhães (1994, p.102) refere-se à construção do lugar partindo das diferentes tipologias que integram uma estrutura em determinado contexto como sendo

A combinação destes elementos ou conjuntos, em totalidades complexas, que dá origem à imagem de um Lugar, permitindo que as pessoas se orientem no espaço e ajudando à construção do sentimento de identificação com esse Lugar, o que pressupõe a existência dum sentimento de pertença em relação ao mesmo.

Desta forma, os lugares enquanto áreas definidas da cidade, podem ser analisados desde o ponto de vista material, onde se assinalam as atitudes das gerações e onde o processo de apropriação se realiza no e através da utilização dos espaços, que surgem como uma condição necessária à vida. Não somente como dimensão material, o “[...]lugar significa muito mais do 
que a sua localização, pois encerra significados culturais que sintetizam e representam o meio que o envolve, bem como a situação existencial em geral" (MAGALHÃES, 1994, p.100).

O papel da concepção projectual ao nível dos elementos constituintes é muito importante no processo de criação. Para que possa haver uma reciprocidade entre os elementos formais e os indivíduos, pois enquanto espaço material ele assenta numa base física de abordagem, em que os câmbios são menores que em termos de significados. A consciência da forma de cada espaço e das suas relações é primordial num bom projecto. Estas formas não têm de responder necessariamente a padrões perceptivos evidentes, a geometria elementar ou a simetrias bilaterais simples - se bem que tampouco há razões para descartá-las. Dotar o espaço de forma é dotá-lo de um sistema de ordem e implica usar os mecanismos capazes de fabricar esta ordem (LLORENS, 1994). Por esta razão se torna necessário a compreensão do lugar de vida das populações em todas as suas componentes, pela importância no direccionamento do desenho urbano visionando a integração do espaço público com os seus habitantes, para que o mesmo não se torne numa ténue versão do desenho do lugar como espaço de ser e acontecer. Um dos graves problemas na abordagem prende-se com a incapacidade do homem interagir e transformar o espaço de forma adequada. O espaço foi separado do lugar, dessa forma se tornará no espaço dos objectos. A consideração do homem na expressão do lugar faz sentido porque é através dele que o espaço público se constrói. Castells (1975) trata destas questões a uma escala maior e mais flexível, algo em que a dinâmica é de apreensão directa, em que o sistema de sinais tende a especificar-se num conjunto de relações recíprocas entre o traçado da cidade e os fluxos de circulação. A simbólica metropolitana poderá estar mais nas formas amplas e difusas das auto-estradas urbanas e espaço verdes do que concentrada em determinados lugares. Penso que Castells tende a direccionar a sua abordagem para esta escala, porque necessariamente a observação dos planeadores e daqueles que trabalham de forma mais directa o espaço público, assenta num base de abordagem mais específica e directa, de um espaço mais concreto. A cidade é constituída de lugares, todos eles fazem parte da sua simbólica, pois expressam sempre algum significado e a caracterizam.

Em jeito de conclusão, é importante entender as especificidades do lugar, marcado pelo sentido de pertença dos indivíduos, pois a identidade humana pressupõe a identidade do lugar, pelo que a estabilidade do lugar é uma necessidade fundamental (NORBERG - SCHULZ, 1994). Na abordagem de Tuan (1983, p.197) os lugares

Podem-se fazer visíveis através de inúmeros meios: rivalidade ou conflito com outros lugares, proeminência visual e o poder evocativo da arte, arquitectura, cerimónias e ritos. Os lugares 
humanos tornam-se muito reais através da dramatização. Alcançase a identidade do lugar pela dramatização das aspirações, necessidades e ritmos funcionais da vida pessoal e dos grupos.

A forma do espaço público prende-se não somente com linhas e figuras geométricas, mas com algo intrínseco ao próprio espaço, mas que se define através do desenho. Contudo este desenho tem uma organização definida por técnicos pelo poder local, ou seja um objectivo, que pode ser encontrado nas formas ou não. Depende da capacidade de produzir um espaço à imagem da cidade e dos usuários. A forma manifesta uma vontade, um objectivo, uma organização política, um conceito e um significado, mesmo que alienado do que ela está reproduzindo no momento em que se concebe. A forma não existe por si só, mas comporta uma série de objectos materiais e imateriais, assim como um conjunto de acções que são determinantes na sua projecção urbana e no modo como as pessoas se apropriam dos espaços. A apropriação efectua-se pela e na forma dos espaços públicos, conduzida pelas suas componentes. Cada pessoa encontra entre os diferentes objectos e acções, uma configuração que Ihe confere uma identidade, um gosto particular, que vai fazer com que se aproprie do espaço. É nesse momento que o espaço se torna num lugar, único e intransponível, porque têm um valor identitário, tem uma estrutura organizacional e social. Considerando o espaço público o lugar por excelência da cidadania, do encontro e também como pontos estruturantes da malha urbana, definidos por uma tipologia própria, a forma aparece como a determinação do que é e representa o espaço público, e como a sua vivência o transforma num lugar específico.

\section{Referências Bibliográficas}

ARENDT, H. La crise de la culture. Paris: Ideés/Gallimard, 1972.

ARNHEIM, R. La forma visual de la arquitectura. Barcelona: Gustavo Gilli, 1978.

ASCHER, F. Metapolis ou I\$avenir des villes. Paris: Editions Odile Jacob, 1995.

AUGÉ, M. Não-lugares. Introdução a uma antropologia da sobremodernidade. Lisboa: 90 Graus Editora, 2005.

BORJA, J. La ciudad conquistada. Madrid: Alianza Editorial, 2003.

BRANDÃO ALVES, F. Avaliação da qualidade do espaço público urbano. Proposta Metodológica. Lisboa: Fundação Calouste Gulbenkian; Fundação para a Ciência e Tecnologia, 2003.

CARLOS, A. F. O lugar no / do mundo. São Paulo: Hucitec, 1996.

CARLOS, A. F. Espaço-tempo na metrópole: a fragmentação da vida cotidiana. São Paulo: Contexto, 2001. 
CARRERAS i VERDAGUER, C. In: ROBIRA, R T. (coord) (2002). Espais públics. Mirades Multidisciplinàries. Barcelona: Biblioteca Universitária, 2002. p. 95-116.

CASTELLS, M. Problemas de investigación en sociologia urbana. 4 ed. Madrid: Siglo XXI, 1975.

CASTELLS, M. The rise of the network society. Cambridge: Blackweel Publishers, 1996.

CASTRO, A. Espaços Públicos, Coexistência Social e Civilidade. Contributos para uma reflexão sobre os Espaços Públicos Urbanos. Revista cidades, comunidades e territórios, Lisboa, Instituto Superior de Ciências do Trabalho e da Empresa (ISCTE), n.5, p. 53-67, 2002.

CORRÊA, R. L. Dimensões de análise das redes geográficas. Trajetórias geográficas. Roberto Lobato Corrêa (Coord.). Rio de Janeiro: Bertrand Brasil, 1997. p.107-118.

COSTA, P., PEREIRA, M.A. A alienação do sujeito no cotidiano das cidades. Rio Claro: UNESP, 2004.

DANTAS, A. C. Planejamento urbano nos anos 90: negociações entre as esferas pública e privada. 1997. 219 f. Tese (Mestrado em Planejamento Urbano e Regional) - Faculdade de Arquitetura, Universidade Federal do Rio de Janeiro, Rio de Janeiro.

EYLES, J. The Geography of everyday life. Horizons. In: GREGORY, D.; WALFORD, R. (Coord.). Human geography. Houndmills: Macmillan Education, 1989. p.102-117.

HABERMAS, J. Mudança estrutural da esfera pública. Rio de Janeiro: Tempo Brasileiro, 1984.

HARVEY, D. Condição pós-moderna. São Paulo: Loyola, 1992.

INDOVINA, F. O Espaço público-tópicos sobre a sua mudança. Revista Cidades, Comunidades e Territórios, Lisboa, Instituto Superior de Ciências do Trabalho e da Empresa (ISCTE), n.5, p.119-123, 2002.

LAMAS, J.P.G. Morfologia urbana e desenho da cidade. Lisboa: Fundação Calouste Gulbenkian, 1992.

LEFEBVRE, $H$. La survie du capitalisme-la re-production des rapports de production. Paris: Éditions Anthropos, 1973.

LEITE, A. F. O Lugar: duas acepções geográficas. Anuário do I nstituto de Geociências. Rio de Janeiro: Universidade Federal do Rio de Janeiro, 1998.

LLORENS, M. del M. La ciudad de Carthago Nova: las emisiones romanas. Múrcia: Universidad de Múrcia, 1994.

LYNCH, K. A imagem da cidade. Lisboa: Edições 70, 1980.

MAGALHÃES, M. R. Paisagem urbana e interface urbanorural. Paisagem. Lisboa: DGOTDU, 1994.

MAGALHÃES, M. R. Arquitectura paisagista - Morfologia e Complexidade. Lisboa: Editorial Estampa, 2001. 
MELLO, J. B. F. Geografia Humanística: a perspectiva da experiência vivida e uma crítica radical ao positivismo. Revista Brasileira de Geografia, São Paulo. n.52, p. 91-115, 1990.

MALARD, M. O corpo como referência, e o arranjo dos objetos. Revista electrónica: Introdução à Arquitectura e Urbanismo. Texto 1. 2007. Disponível

em: http://www.arquitetura.ufmg.br/pri/introducao/Introducao\% 20-

Texto\%201.doc. Acesso em: 27 de Maio de 2007.

NORBERG-SCHULZ, C. Existencia, espacio y arquitectura. Barcelona: Blume, 1975.

NORBERG-SCHULZ, C. In: MAGALHÃES, M. R. (1994). Paisagem Urbana e Interface Urbano-Rural. Paisagem. Lisboa: DGOTDU, 1994. p. 97-120.

POL, E. La apropriación del Espacio. In: L. Iñiguez; E. Pol (eds), Cognición, representación y apropriación del espacio. Barcelona: Publicacions Universitat de Barcelona, 1996. p.45-62.

PRETECEI LLE, E. Mutations urbaines et politiques locales. V.1. Paris: Centre de sociologie urbaine. Institut de recherche sur les sociétés contemporaines, 1998.

RELPH, E. C. Place and placelessness. London: Pion, 1976.

RELPH, E. C. As Bases Fenomenológicas da Geografia. Revista de Geografia, Rio Claro, n.4, p.1-25, 1979.

RIBEIRO, J. A cultura e a (des)diferenciação do espaço público. In: IV Congresso Português de Sociologia, 2000. Actas do IV Congresso Português de Sociologia Coimbra, p.1-14, 2000.

ROBIRA, R. T. (coord). Espais públics. Mirades Multidisciplinàries. Barcelona: Biblioteca Universitária, 2002.

SANTOS, M. Espacio y Método. Geocritica. Cadernos Críticos de Geografia Humana, Barcelona, Publicacions i Edicions UB, n.65, Septiembre 1986. 57 páginas.

SANTOS, M. Metamorfosis del espacio habitado. Barcelona: Oikos-tau, 1996.

SANTOS, M. La naturaleza del espacio. Técnica y tiempo. Razón y emoción. Barcelona: Editorial Ariel, 2000.

SASSEN, S. The global city: New York, London, Tokyo. New Jersey: Princeton University Press, 1991.

SERPA, A. Espaço público e acessibilidade: notas para uma abordagem geográfica. Revista GEOUSP - Espaço e Tempo, São Paulo, n.15, p.2137, 2004.

SOJA, E. Geografias pós-modernas: a reafirmação da teoria social crítica. Rio de Janeiro: Jorge Zahar, 1993.

TUAN, Yi-Fu. Place: an experiential perspective. Geographical Review, United Kingdom, n. 65, p.151-165, 1975.

. Espaço e lugar. São Paulo: Difel, 1983. 


\section{Endereço para correspondência}

Carla Alexandra Filipe Narciso

Universidade de Lisboa, Faculdade de Letras, Departamento de Geografia, Alameda da Universidade, 1600-214, Lisboa, Portugal

Endereço eletrônico: carla-narciso@iol.pt

Recebido em: 01/10/2008

Aceito para publicação em: 25/08/2009

Editor responsável: Deise Mancebo 